Type of paper: Research article

\title{
Title: AN EXPLORATION INTO THE OPPORTUNITIES FOR BLOCKCHAIN IN THE FRESH PRODUCE SUPPLY CHAIN
}

\author{
Ralph Kwadwo Osei ${ }^{\mathrm{a}}$, Maurizio Canavari ${ }^{\mathrm{b}}$, Martin Hingley ${ }^{\mathrm{c}}$ \\ a Alma Mater Studiorum-University of Bologna, Bologna, Italy; MSc candidate; \\ ralphkwadwo.osei@studio.unibo.it \\ b Alma Mater Studiorum-University of Bologna, Bologna, Italy; Associate Professor;
maurizio.canavari@unibo.it
}

${ }^{\mathrm{c}}$ University of Lincoln, Lincoln, UK; Professor; mhingley@lincoln.ac.uk

\begin{abstract}
Blockchain is a data management innovation that allows the linkage of successive records regarding a digital entity, and to store them into a shared, decentralized, distributed and retroactively unchangeable data structure. Each bit of information related to the recorded events contains the public key of the owner, therefore, the whole record is formed by a chain of transactions with blocks of information identifying where the transaction was generated from and its current destination (Nakamoto, 2008). Blockchain is the technology behind Bitcoin, an online currency that was first introduced in 2009. The technology makes it possible to conduct business between members within the network without relying on third parties as guarantors to prove transaction integrity, thus increasing speed and reducing cost of transaction. Moreover, the transparency posed by the technology makes it possible to trace goods and services through all stages, making the technology a unique tool that can be assimilated by, for example, the Agrofood supply chain systems. Specifically, Blockchain is being tested in a pilot project in the UK meat (Beef) industry by the FSA (Food Standards Agency) and the slaughterhouses, with IBM Blockchain platform to ensure full transparency and compliance with regulations, (Evenstad, 2018). However, the uptake of Blockchain in the fresh produce (fresh and fresh, short-life processed fruit, vegetables, salads) supply chain is lagging, in the United Kingdom, and remains untested and limited to literature, models and specific case studies in the United States of America and France.
\end{abstract}

The study aims at understanding how prepared stakeholders are in adopting Blockchain for their operations.

An inductive qualitative method was employed through non-structured interviews with three companies and one consumer focus group. The interviews were guided by seven (7) open-ended questions, which were unstructured. The collected data was analyzed with axial coding through constant comparative methods. Seven (7) themes were identified as factors influencing the adoption of Blockchain in the fresh produce supply chain in the UK. These are, novelty of the technology, complexity of the fresh produce supply chain in UK, level of product transformation, technological compatibility with operations, cost and value, Customer (retailer) push for adoption, and public/consumers opinion. The adaptation of Blockchain by the current fresh produce supply 
chain in the UK and the EU at large will come about when concerns on Novelty, and complexity of supply chain systems are fully addressed.

Keywords: Blockchain, fresh produce, supply chain, food safety, traceability, internet of things, smart contract 


\section{INTRODUCTION.}

Blockchain technology (henceforth Blockchain) is a data management innovation that allows to link together successive records regarding a digital entity and to store them into a shared, decentralized, distributed and retroactively unchangeable data structure. It is also known as distributed ledger technology (Tripoli, and Schmidhuber, 2018). Each bit of information related to the recorded events contains the public key of the owner, therefore the whole record is formed by a chain of transactions with blocks of information telling where the transaction generated from and its current destination (Nakamoto, 2008).

Blockchain has a great market visibility and applications in different businesses having been suggested and introduced, especially in the financial sector, (Almeida, Albuquerque, and Silva, 2019). It provides a means to ensure permanency of records and potentially to facilitate the sharing of data between disparate actors, for example, in a food value-chain, leading to a paradigm shift facilitating transparency and trust in food chains that ensures food integrity (Bessems, and Bril, 2017). To date, there have been numerous publications, articles, presentations, blogs and demonstrations of the applications of Blockchain in the distribution of information within the Agro-Food industry. However, shortcomings are in failure to see a widespread technological applicability in the supply chain management of Agro-products, specifically fresh produce. (White, 2017)

Despite growing attention from the Agro-Food industry, the application of Blockchain is not on the increase but still limited to the drawing board, with few companies taking advantage of the benefits that the technology has to offer. Given the rapidly increasing level of digitization and demand for data and product integrity, Agro-food is in a unique position to explore opportunities of new innovations such as those offered by Blockchain technology. Left uncoordinated, this can result in the waste of resources and missed opportunities for businesses and society as a whole, (Ge, Verdouw, Wolfert, and Bogaardt, 2017). This study is motivated by the need to understand why the adoption of Blockchain is not growing in the fresh produce supply chain. The context chosen is the United Kingdom, which is in many ways at the forefront of production, value-adding and trade in fresh produce; as a globally significant originator, but also consumer of fresh produce. The UK also has sophisticated stakeholders along the supply chain from production to consumption.

The aim of this paper is, therefore, to investigate the readiness of the fresh produce supply chain main stakeholders towards the adoption of Blockchain, and to identify major drivers and barriers surrounding its adoption.

The United Kingdom fresh produce supply chain has been identified as the context for the study. As noted above, the UK was selected as a case study due to the complexity of their supply chain system, characterized by long and short supply chain systems based on the source of raw materials, either from internally produced or imported from other countries, (Wilson, 1994). The UK supply chain is also known to be technologically adoptive to new innovations and noted in being the largest ecommerce market with an E-GDP of 7.16 in Europe, (Tuschl, 2017), making the United Kingdom an important case to study if application of Blockchain is not on the increase after years of introduction. 
The study target group consisted of two stakeholder types: production companies and consumers. The companies were selected based on three criteria; they must be physically present and operating in the United Kingdom, they must handle fresh produce at a point in their operations and should be sharing data and/or information across their current supply chain system. Consumers needed to be consuming fresh produce in the UK to be eligible for the study.

An inductive qualitative research approach was adopted. Secondary data was collected from literature publications, articles, corporate webpages, newsletters, government and private regulators websites, national and international media reports. Primary data was collected through interviews with participants, in the case of company managers, and through a focus group in the case of consumers. Four semi-structured interviews - one telephone and three face to face interviews were conducted. One focus group with six (6) consumers was organized based on the same interview guideline. The interview guideline consisted of seven (7) unstructured open-ended questions which focused on different sources of information including knowledge on Blockchain and readiness to adopt the technology for implementation.

The paper is organized as follows: Background and Motivation, Material and Methods, Results and, Discussion, and Conclusions. 


\section{BACKGROUND AND MOTIVATION}

Blockchain has been reported to offer solution to food safety issues facing the food industry, specifically issues relating to traceability, transparency and trust, (Kairos Future, 2018). Despite the reported benefits of using Blockchain solutions, fresh produce supply chain stakeholders including private companies, government agencies and consumers are neither encouraging nor stimulating use of the technology in the sector.

The release of a white paper from Satoshi Nakamoto in 2008 on Bitcoin was a game changer in the area of information technology. The proposed system of payment that allowed parties to deal directly with each other without going through financial institutions that serve as sureties, and also prevent double spending through time stamping of transactions, by binding them into an ongoing chain of hash-based proof of work; that forms a record that cannot be changed without redoing the proof-of-work (Nakamoto, 2008). This innovation in data security, and distribution opened new doors to other business aside the financial sector that required improvement in sharing real time information among partners without depending on a central system that can be easily manipulated in favor of the party owning the system. The fresh produce supply chain is among such sectors that seeks to improve their current operations due to the complexity of their supply chain systems, (Abeyrantne, and Monfared, 2016).

Blockchain is demonstrated as a chain of transactions linked to each other with a digital signed hash of the previous transaction and the public key of the next owner, which forms a chain of transactions with blocks of information telling where the transaction generated from and its destination, (Nakamoto, 2008).

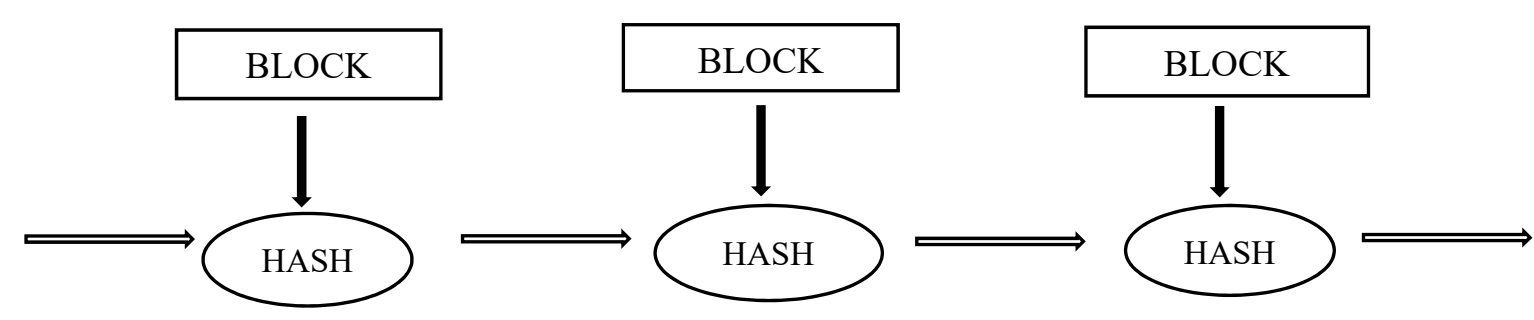

Figure 1: The Blockchain scheme by Nakamoto.

Bitcoin and Ethereum, are the two most known cryptocurrency platforms in the financial market, and are based on Blockchain technology designed to promote a trust mechanism in a peer-to-peer network based on the consensus of majority of the nodes in the network (Vujičić, Jagodić, and Ranđić , 2018). Ethereum Blockchain offers the opportunity to integrate the technology into the supply chain management of fresh produce due to their smart contract characteristics that allows actors to design contracts which are self-executing once the parameters are meet. (Buterin, 2013).

By digitally recording the identity of goods, Blockchain provides a permanent, immutable record for every food product as it travels from farm to folk. This transparency gives processors, 
wholesalers, distributer, food service, food trucks, and consumers' information about where their food comes from, how it was processed and a full account of its movement along the supply chain, (Maras, and Elliot, 2017). According to Maras, and Elliot everyone is a winner under blockchain due to the accountability and transparency that comes with the technology.

Within traceability and control of goods such as food, public Blockchain platforms like Bitcoin and Ethereum seems to be out the question. Today only private Blockchain is used for supply chain systems due to high transaction cost and low capacity of public Blockchain platforms. These private Blockchain providers include IBM, Chainvine, Ripe, Provenance and others.

IBM, for example, focuses on solutions for large enterprises like Maersk and Walmart, with a platform called Hyperledger Fabric that has two major advantages over the rest of the providers. IBM's Blockchain platform can integrate with existing EDI (Electronic Data Interchange) information in companies ERP-systems (Enterprise Resource Planning systems), and is capable of merging with GSI standards (Global Standards Initiatives) systems to prove food safety and quality. These solutions facilitate integration of Blockchain with existing systems used by retailers, wholesalers and food manufacturers in the fresh produce supply (Kairos Future, 2018).

After successfully conducting a pilot project in October 2016 with IBM on two proof of concepts (POCs), mangoes from Mexico and pork in China, Walmart together with IBM and their foundation partners moved rapidly to scale, test and implement Blockchain-enabled technology on several strategically selected SKUs (Stock Keeping Units) including private and supplier brands. The report states that "As at May 2018 Walmart had already tracked nearly twenty-four SKU's involving 2.6 million food packages across 166,000 traceability events on Blockchain. In terms of traceability speed, the system took 2.2 seconds to trace a mango from the shop level to a farm in Mexico, whiles it took the traditional system (combined effort of a centralized and paper/pen) seven days to trace the product to the source". (Yiannas, 2018).

Of all said about the technology, the adoption of the technology is not caching up with the popularity it is gaining in literature. The rapid but unpredictable direction of Blockchain innovation is making the technology particularly hard for commercial organizations and government agencies to make strategic decision on how to respond to Blockchain technology, $(\mathrm{Ge}$, Verdouw, Wolfert, and Bogaardt, 2017).

As such, this study is undertaken to help us understand why the adoption of Blockchain is not growing in the fresh produce supply chain, in the United Kingdom, but remains untested and limited to the literature, models and specific case studies in the United States of America; by Walmart and in France by Carrefour. 


\section{MATERIAL AND METHODS}

A qualitative investigation based on individual interviews with industry stakeholders (and consumers was conducted in the United Kingdom for this research. Given the exploratory nature of the research problem, a qualitative approach was selected for this research in order to enable participants to share their views on Blockchain, as a topic and its application in the fresh produce supply chain. Moreover the newness of the technology, is making numerical data on Blockchain difficult if not almost impossible to collect (White, 2017).

The United Kingdom fresh produce supply chain was selected due to its complexity and proactiveness towards innovation. The population consisted of food manufacturing companies and a focus group of consumers. The companies were selected based on three criteria; being physically present and operating in the United Kingdom, which they should handle fresh produce at a point in their operations, and should be sharing data and/or information across their current supply chain system. For the consumer group selection, these participants should be consuming products of fresh produce origin and be physically present in the United Kingdom.

Interviews with company officials (Directors and managers) and with a group of consumers form the primary source of data collection. Four semi-structured interviews - one telephone and three face to face interviews were conducted with the participants.

Prior to the interview, a formal request for appointments was sent to all companies a month before through emails. After interviewees has accepted the request for interviews, an appointment was settled on in agreement with the interviewee on day, time, and preferred medium of contact if not going to be face to face, all in the convenience of the interviewee. After agreeing on the appointed date, an overview of the research was sent to participants to familiarize themselves on the topic to be discussed. This overview entailed what Blockchain is, (its application in the fresh produce supply chain) and the aim of this research. Another email was sent a day before the agreed date to remind participants and to make changes if they were not going to come through with the scheduled plan. After the interview, an appreciation email were sent to the participants for their contribution to the study.

For our consumer focus group, a formal request for interview was done with a courtesy visit to the place of weekly meeting and arranging to have a discussion with them a week after, at their meeting place. The group accepted and shared their opinions on Blockchain in fresh produce supply in the following week.

The interview guide consisted of seven (7) semi-structured (open-ended) questions:

a) How much do you know about Blockchain Technology?

b) Can you briefly describe your current system of information sharing between you and your suppliers?

c) How flexible is your company in the adoption of new technologies?

d) Can you identify any opportunities you might derive in using Blockchain technology?

e) What will be some of the challenges in the adoption of Blockchain Technology to your operations? 
f) If Blockchain technology is offered to you, will your company be readily adopting and why?

g) As a consumer, what information do you want food processing and packaging companies to provide you and why?

The design of the schedule drew on different sources of information including knowledge about Blockchain and stakeholder's readiness to adopt the technology in their operations. Informed consent was obtained from all participants, and their views were expressed freely on the subject.

Although the identities of interviewees are not given due to privacy protection, the main characteristics of the stakeholders and the position of the interviewees are represented in Table 1

Table 1: Table of representation

\begin{tabular}{|c|c|c|c|c|c|c|}
\hline Stakeholders & Actor Type & Interviewee position & Prior Blochchain & \multicolumn{3}{|c|}{ Coverage } \\
\hline & & & Knowledge & Fruits & Vegetable & Both \\
\hline COMPANY A & $\begin{array}{l}\text { Potatoes packing and } \\
\text { distribution company }\end{array}$ & $\begin{array}{l}\text { Director for } \\
\text { innovation }\end{array}$ & Yes & & $\sqrt{ }$ & \\
\hline COMPANY B & $\begin{array}{l}\text { Food manufacturing } \\
\text { company }\end{array}$ & $\begin{array}{l}\text { 1. Commercial } \\
\text { Director. } \\
\text { 2. Technical } \\
\text { Director } \\
\text { 3. Supply Chain } \\
\text { Director } \\
\text { 4. Production } \\
\text { Director }\end{array}$ & $\begin{array}{l}\text { No } \\
\text { No } \\
\text { No } \\
\text { No }\end{array}$ & & & $\sqrt{ }$ \\
\hline COMPANY C & $\begin{array}{l}\text { Food manufacturing } \\
\text { company, (fresh } \\
\text { prepared food) }\end{array}$ & $\begin{array}{l}\text { 1.Process } \\
\text { development } \\
\text { manager }\end{array}$ & No & & & $\sqrt{ }$ \\
\hline CONSUMERS & $\begin{array}{l}\text { Fruits and Vegetable } \\
\text { consumers, mainly } \\
\text { Vegetarians and } \\
\text { Vegans }\end{array}$ & $\begin{array}{l}\text { 1. FG, A.1. } \\
\text { 2. FG, A.2 } \\
\text { 3. FG, A.3 } \\
\text { 4. FG, A.4 } \\
\text { 5. FG, A.5 }\end{array}$ & $\begin{array}{l}\text { No } \\
\text { No } \\
\text { No } \\
\text { No } \\
\text { No } \\
\end{array}$ & & & $\sqrt{ }$ \\
\hline
\end{tabular}

Face to face interviews were conducted on the premises of the companies being interviewed, either at the office of the interviewee as in the case of Company A or in the board room as of Company B. For Company $\mathrm{C}$, the interview was conducted over the telephone. The interviews were recorded with a digital audio recording device and a note book. The note book was for taking short notes of important quotations and points from the interviews and to follow through all stipulated questions. 
The recorded interviews were transcribed by playing back the recordings and writing down quotations verbatim. Microsoft Word office 365 Dictation set to English (United Kingdom) software was used for electronic transcription by plugging an audio cable from the digital audio recorder to a computer with Microsoft Word on Dictation mode.

The interview transcripts were compared and merged into one document for analysis. The data was then processed, analyzed and coded inductively, comparing quotations among interviewees and also with selected research findings carried out by researchers on the adoption and implementation of Blockchain in other sectors. An axial coding, characterized by constant comparative method, was used to develop categories of central themes for analysis. 


\section{RESULTS AND DISCUSSION}

The results of the interviews are derived from the elaboration of the interview and consumer group discussion transcripts that allowed identification of seven major themes: novelty of technology, complexity of fresh produce supply chain, level of product transformation, technology compatibility with operations, customer (retailer) push, public/consumer opinion, cost and returns on investments, as the underlining factors for the adoption of Blockchain in supply chain of fresh produce in the United Kingdom. These themes are influenced by drivers and barriers including:

- Retailers influence on the supply chain system

- Interest of operators to increase trust and speed of information flow among members of the supply chain

- Source of produce. Homegrown or imported

- Transformation processes and food safety risk associated with food products

- Interest to achieve a competitive advantage

- Consumers' willingness to pay and interest in decision making

- Fear of disruption on current processes

- Current operating systems and antagonizing competition

- Lack of technology demonstration (cost and payback) and education

The newness of the technology coupled with low publicity of its application in the supply chain of Agro food products, is contributing to the slow adoption of the technology. Blockchain is a new topic for literature and is still an unknown to most industries, (Huumo, 2016). Novelty of Blockchain can be a pull and at the same time a push for companies to adopt the technology. It becomes a barrier when there is anticipated fear of disruption on current processes. Companies are looking over their shoulders as to who goes first, (Gausdal, 2018). While technologies such as mobile communication and social media are considered mature, there are technologies including Blockchain that are still only subjected of research and funded projects or others that are used in commercial level, but their use is not widespread, and they are still facing inherent problems, (Meyer-Larsen, 2014).

"We have come across a number of platforms to allow us identify our information points for reporting globally, these includes horizon scanning, Codex and other models out there, but not specifically Blockchain Technology; and we are not aware of it" (Technical Director of Company B).

"Blockchain Technology is not something am particularly familiarized with. No one has ever approached me about the technology and I have never discussed it before" (Product Development Manager of Company C).

All interviewees for this research had not come across Blockchain as an application technology for operation in the fresh produce supply chain. Although the Innovation Manager of Company A had prior knowledge about the technology through literature and articles, as his job includes research into new technologies concerning supply chain systems. 
Figure 2: Blockchain features, drivers and barriers.

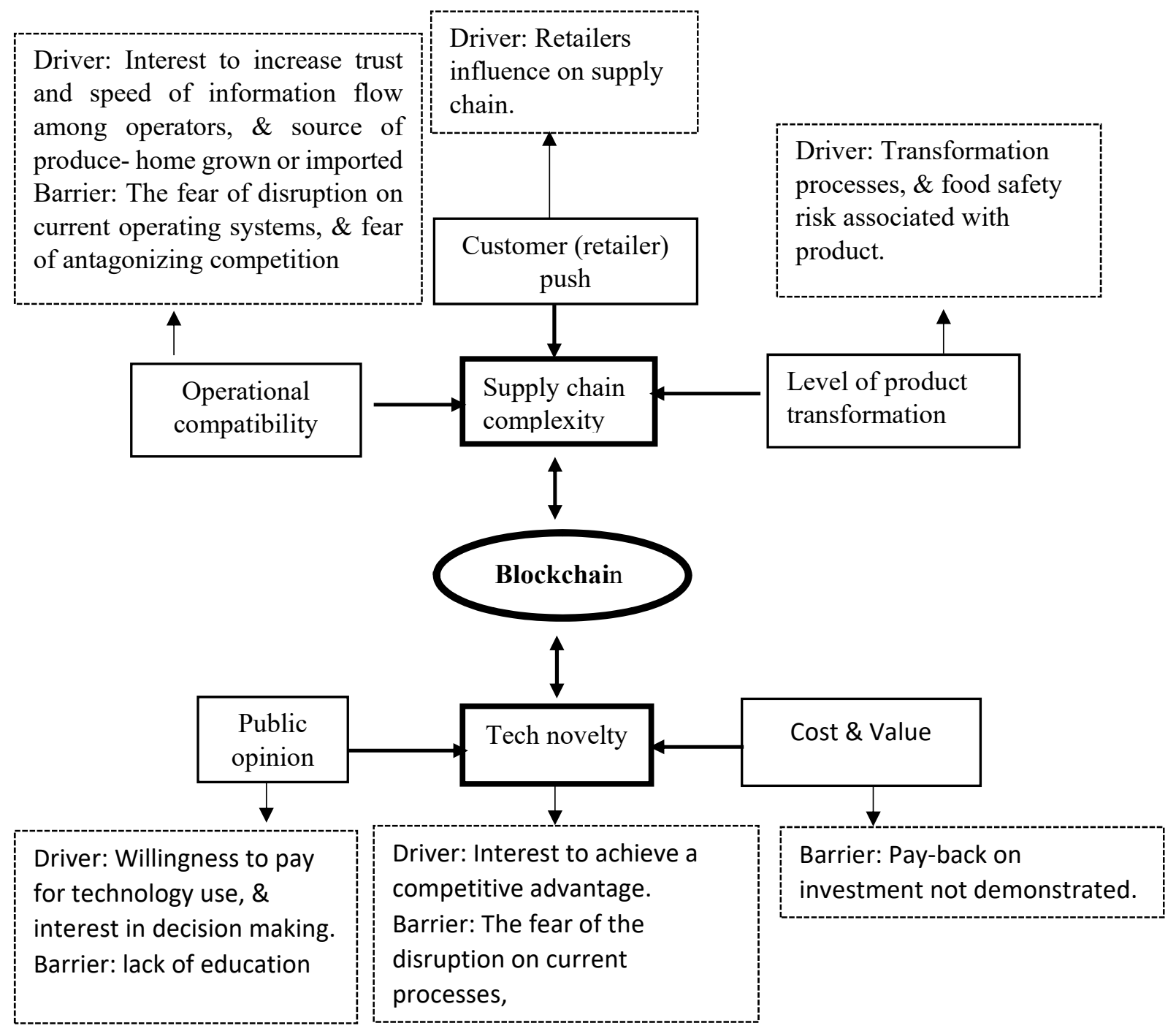

Source: Authors elaboration.

"The technology will connect points of data collection and therefore improve Traceability and transparency within the supply chain. Blockchain is on our radar, but currently we are not running any project on the application of the technology to our supply chain”. (Innovation Director of Company A).

The UK is the most sophisticated in the retailing of fresh produce (Hingley, Lindgreen, and Casswell, 2006), (Wilson, 1994). The sophistication in UK fresh produce industry comes mainly as a result of the source of fresh produce, imported or produced in the UK. The supply chain of vegetables is seen to have a high direct supply from producers (Farmers) to 
retailers in the UK than other countries in the EU as these countries practices co-operative systems to auction their fresh produce to the market, (Hingley and Sodano, 2010) (Wilson, 1996).

Producers sell vegetable products directly to retailers through their distribution centers. Supermarkets are contracting directly with producers and setting up packing facilitates at farms in the UK and abroad so that packed produce can be delivered directly to distribution centers, (O'Keeffe, and Fearne, 2002), (Hingley, 2005a). This mode of supply chain operations shortens the journey of products and their accompanying information as they go through few steps before reaching the final consumer. Blockchain in such a supply chain environment where operators are easily identified in a short chain will be hindered by the complexity of the food supply chain system.

\section{"Traceability from the prospective of consumers and customers (retailers) are fully meet with our current system" (innovation Director, of Company A).}

The fresh produce industry in the UK is structured to increase visibility among operators as their current systems although centralized allows members to share information easily. The current system has been proven over the years by operators, who has now gained experience in its operations. Although the technology has been implemented by Walmart and Carrefour, it has not been tried, and proven in the UK's complex supply chain environment. The fear of disruption on current processes is a barrier for adoption as the risk of adopting innovations that has not been proven pushes operators away.

\section{"The challenges will be management of the project in terms of software/hardware integration into our current system, and a clear benefit identification for our business" (Process Development Manager of Company C).}

"It is difficult to say whether or not we will be able to implement the technology at this stage, unless the technical and economic aspects of the technology is fully understood" (Commercial Director of Company B).

One of the main constraints for most technology solutions is the unsolved issues of the standardization of communication technology and protocols. Before solutions are adopted by the industry on a large scale, issues of technology incompatibility and lack of standardization must be resolved, (Meyer-Larsen, 2014). Questions surrounding Blockchain compatibility with complex supply systems has not been answered with a demonstration in the UK setting. IBM's Hyperledger Fabric suggests to solve this issue of compatibility, but due to the novelty of the technology, operators continues to worry on how applicable is Blockchain with their current supply chain systems and why they should adopt it if the current system is serving its purpose, (Kairos Future, 2018).

Fresh produce goes through a speedy supply chain network in the UK. Produce quality is maintained by reducing risk associated with contamination through mishandling, therefore reducing food waste through the timely delivery of products at the stores from farms. For companies that handle single products like potatoes, the need for Blockchain is minimal, if not 
needed at all. Produce undergoes further processing to reduce food safety risk associated with the fresh produce. Risks associated with certain food groups are driving regulators and operators to seek for technologies such as Blockchain to improve visibility in operations. For example, after the horse meat scandal in the UK in 2013, the meat industry was tagged as a high-risk sector, forcing operators of the supply chain and the Food Standard Agencies to look for innovative ways to reclaim the industries lost dignity. Among the solutions, is an ongoing pilot project on beef traceability with Blockchain, (Pierce, 2018), (Evenstad, 2018).

"There isn't a compelling and commercially valuable need of the technology now, as the fresh produce sector is not a high-risk area compared with the meat industry that needs to redeem its image after the horse meet scandal in the UK." (Innovation Director of Company A).

Although operators might not see a compelling need for a change, customers (mostly Retailers) can influence their decision towards the adoption of the technology. The Retailer in the UK is the most powerful commercial partner in the chain, commanding around 70 percent of sales volumes and continuously increasing every year, (Wilson, 1996). They are best described as "Channel Captains" due to their influence over other actors within the food chain, (Hingley, 2005b). Retailers have the power to initiate a program for their suppliers to adopt and also discourage the adoption of any technology.

"Should there be a need from the consumer or customer for the application of Blockchain Technology, there will be adoption should the company see a need for the application of Blockchain" (Innovation Director of Company A).

"The simple answer to that will be based on economics. Example, if Tesco says to us that we are adopting Blockchain as a system for supply chain visibility, we as a company will value our chances which is, what is the cost if we buy into it and what is the cost if we don 't and that is it" (Commercial Director of Company B)

"Yes, we are led by what the retailers tell us, because they hold the guns and are the dominant players. Without them our products do not get to the consumer" (Production Director of Company B).

All participants interviewed for this research agreed on adopting Blockchain for operations should Customer (Retailers) request of the technology implementation in the supply chain network. It has been observed that large producers and co-operatives considers large retailers as good buyers due to the large amount of produce purchased (Canavari, Centonze, Hingley, \& Spadoni, 2010), and will like to maintain them by satisfying their demands for improvement should retailers request for a change.

"Our customers are our retailers and we will do anything to please them and to keep them happy” (Process Development Manager of Company C)

"My fear is that, I think this technology is going to be led by the retailers and we will not be given a chance" (Commercial Director of Company B) 
For consumers, retailers and the government are the influential agents that can bring about a change in the current food system.

I think Blockchain Technology has to be pushed by retailers or someone in government, most of the time demands of the public are denied" (FG, A.1).

UK fresh produce supply chain is also characterized by the importation of products from other countries. The United Kingdom is among the three leading direct importers of fresh fruits and vegetables in the EU, and a major destination of imported fruits and vegetables from EU, (CBI, 2015). The complexity of such a wide network from production to retailing is driving operators in this sector towards new innovations to improve trust and speed of information shearing among operators.

Figure 3: Supply chain model-long chain

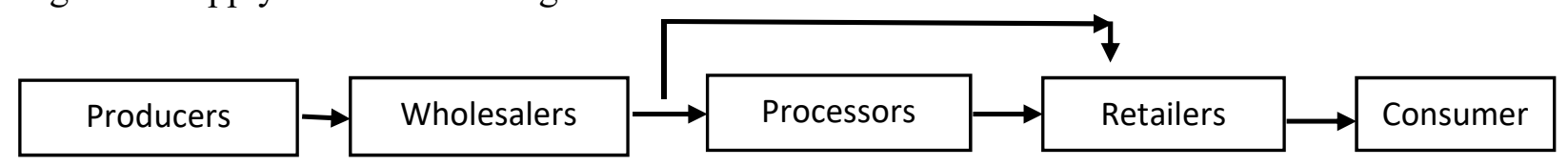

Source: Authors elaboration.

The above fresh produce supply chain model in the UK is commonly practiced by food manufactures that require certain ingredients that are not in production in the UK, and by retail chains that needs to stock fruit and vegetable products that are out of season or cannot be produced in the country.

Due to the complexity of this kind of supply chain model, the system is faced with challenges of data management, lack of trust among members, and high operating costs. Data management in terms of data collection, distribution and storage on a centralized system delays information flow across the network as members do not have systems for real time data sharing:

"We are currently operating on a system that allow our suppliers and national authorities to supply us documents 10 days after the products has been shipped from the port to us here in the United Kingdom" (Technical Director of Company B).

With the opportunities offered by Blockchain in increasing transparency, and trust in supply chain systems, companies that are challenged by the current operating system would be interested in the adoption of Blockchain into their operations:

"If this technology is out there, then is a game changer for the food industry and we at a point has to make a decision to adopt it in the near future because that is what the food industry is supposed to look at globally" (Commercial Director of Company B).

"Produce does not grow in the UK all year round so we source for our raw materials around the world where it is growing around that time. We are very aware that Brexit may have a huge impact on us in terms of product and information flow with the 
current system, but I believe that the impact is unknown, and we will see the best solution for this when we get there" (Process Development Manager of Company C).

The Commercial Director for Company B agrees to the need for a change towards the adoption of Blockchain as his company handles hundreds of ingredients imported from other countries and admits difficulties in handling information coming from their suppliers, as they are often delayed and fear of tampering with data by their providers.

Again, the degree to which fresh produce is transformed from its raw state to finished product contributes to management's decision in adopting Blockchain. Often, it is difficult for companies to trace each and every step in the journey of a specific product back to its origin of production due to lack of records, data quality and reliability (Meyer-Larsen, 2014). Most long supply chain systems of fresh produce may have processing steps along the chain due to the perishable nature of produce. Product transformation involves complex process to produce products of semi-process and/or fully transformed products. Food manufacturing goes along with information management as an integral part of the process, and these information must be provided to authorities for certification and verification of practices in the industry. Blockchain is being looked at as the solution to the inefficiencies in data management by these food manufacturing companies:

"If anybody is going to sell us a Blockchain system, then they should be able to look up to the size of our business and not only to our business but to our supply chain. We are a huge, diverse and complex business responsible for over 350 SKU's, 6,000 different ingredients from 500 different suppliers. This Blockchain Technology is supposed to be able to address these complexities at a reasonable cost" (Commercial Director of Company B).

One of the most influential factors that influence innovation adoption, was cost (Meyer-Larsen, 2014) and this came up throughout the interviews. All participants want providers of Blockchain solutions to come up with costings surrounding technologies adaptation, and implementations in terms of software costs; these usually being license costs, hardware costs referring to purchasing and maintaining equipment, training costs, and operational costs:

"Blockchain, just like other technologies will have its challenges including. Cost of the technology" (Innovation Director of Company A).

"It will come down to cost and payback, we will need a capital expenditure proposal to demonstrate that the money we are spending is going to be paid back over a certain period; that is, the scale of the project and the payback time should be acceptable. We need to demonstrate the expected results and assure that is going to add value and payback. It will come down to what will benefit us as a company and where that cost will be demonstrated, for example, will the cost be passed down to the consumer or what?" (Process Development Manager of Company C)

"It is difficult to say whether or not we will be able to implement the technology at this stage, unless the technical and economic aspects of the technology are fully understood" (Commercial Director of Company B). 
Cost is the unknown element surrounding Blockchain adaptation and until this fog is cleared, the adoption of the technology will continue to face challenges. But on the other hand, the wish to work more efficiently utilizing modern information technology opportunities will encourage the adoption of technologies by operators (mostly retailers), of the supply chain (Koc, 2017).

The public, representing the largest stakeholder group in every business venture are asking for more information on what they are consuming, questioning the authenticity of information provided on product package. Consumers feel that they are left out in the decision making processes and want to be heard. Public opinion as collective behavior can play an important role in decisions and act as propaganda for the acceptance /declined projects, (Meyer-Larsen, 2014):

"People want to know the content of their food, others want to trust the food processing companies, proving that people are becoming aware of what they eat and want more information. I think for justice to be done, the scope of activities carried out within the food industry has to be given, but broken down into sections so that we could see everything clearly. (FG, A.1).

"We have been left ignorant for far too long” (FG, A.3)

Blockchain can be easily driven by the public but this is not happening due to its newness to consumers:

"The idea of Blockchain technology to bring transparency into food is good but my only problem is lack of education on it" (FG, A.1).

The public's requests for knowledge are set against the competitive atmosphere surrounding UK's supply chain systems. With the fear of antagonizing competition through wrongful data sharing among competitors, companies are not ready to operate a single platform to manage information for rival companies or operators. Again, opening-up to the public by the food industry with sensitive information, like source of certain ingredients that makes a company unique in the market may hinder the adoption of such technology. Competition in the market is a major barrier for adoption of any innovation. (Meyer-Larsen, 2014). But on the other hand disclosure has become a major issue for consumers.

"From competitive prospective, can a consumer know everything about us that we don't want our competitors to know?" (Commercial Director of Company B).

However, consumers are already aware of the ongoing war between retailers, manufactures and other operator's and wants this sensitive information to be brought to the public.

"I think the implementation of this kind of technology is more political because the industries will not be ready to give such critical information to the public" (FG, A.2).

Consumers foresee a competitive advantage for any operator that implements the technology by paying extra more for the information. This answers the question of the Process Development Manager of Company $\mathrm{C}$, as to whether the cost be pass down to the consumer? 
"I think the public will be willing to pay a little more for information to have a healthy product. Initially this process might make the food price rise a little higher, but as soon as retailers realize that their products are not been bought because consumers are demanding extra information, they will have to sit up and begin to implement it. Spread of the use of the technology will bring down the price of food again to the normal price since inter retail competition will reduce"." (FG, A.3).

The public is willing to see the technology in use, provided the technology is presented in a way they can easily relate to:

"Will there be a reception for this technology? I say yes, but it supposes to come from the angle that the people can relate to, that is how effectively they will present this technology to the public" (FG, A.1)

"We are diverse people and each individual may be interested in different information like place of origin, how is grown, how was it processed, and method of storage. I think individuality in information request should be considered in the design of this system" (FG, A.4).

These identified factors and their contributing barriers and drivers are influencing the adoption Blockchain in the fresh produce supply chain in the United Kingdom.

Table 2: Factors, drivers and barriers contributing to Blockchain adoption.

\begin{tabular}{|c|c|c|c|}
\hline FACTORS & DRIVER & BARRIER & CONTRIBUTION \\
\hline 1.Novelty of technology & $\sqrt{ }$ & $\sqrt{ }$ & $\begin{array}{l}\text { - Interest to achieve a competitive advantage } \\
\text { - The fear of the disruption on current processes, }\end{array}$ \\
\hline 2. Complexity of supply chain & $\sqrt{ }$ & $\sqrt{ }$ & $\begin{array}{l}\text { - Interest to increase trust and speed of information flow among } \\
\text { operators. } \\
\text { - }\end{array}$ \\
\hline $\begin{array}{l}\text { 3. Level of product } \\
\text { transformation }\end{array}$ & $\sqrt{ }$ & $\sqrt{ }$ & $\begin{array}{ll}\text { - } & \text { transformation processes } \\
\text { - } & \text { Food safety risk associated with product. }\end{array}$ \\
\hline $\begin{array}{l}\text { 4. Compatibility with } \\
\text { operations }\end{array}$ & & $\sqrt{ }$ & $\begin{array}{l}\text { - Fear of antagonizing competition between customers. } \\
\text { - The fear of disruption on current operating systems. }\end{array}$ \\
\hline 5. Cost and value & & $\sqrt{ }$ & - Cost and returns on investment not demonstrated. \\
\hline 6. Customer/consumer push & $\sqrt{1}$ & $\sqrt{1}$ & - Retailers influence on supply chain. \\
\hline 7. Public/consumer opinion & $\sqrt{ }$ & & $\begin{array}{l}\text { - Willingness to pay for technology use } \\
\text { - Interest in decision making. } \\
\text { - lack of education }\end{array}$ \\
\hline
\end{tabular}




\section{CONCLUSIONS}

The main purpose of Blockchain is to bring transparency in transactions through trust building, whilst reducing cost, by removing central authorities who act as mediators between parties from the system.

Despite the reported benefits in adoption of Blockchain solutions, fresh produce supply chain stakeholders are neither encouraging nor stimulating use of the technology in the sector.

In our inductive research based on food company managers interviews and one consumer focus group, investigated were seven main themes influencing the adoption of Blockchain: complexity of the UK supply chain, novelty of the technology, operational compatibility with current systems, degree at which finished products are transformed, public opinion on how operators of supply chain systems are treating them, retailers push for supply chain adoption, cost and value on Blockchain implementation.

This study identified, the interest of operators to increase trust and speed of information flow in the supply chain, the source of produce/product- homegrown and /or imported, retailers power on supply chain, complex transformation processes, food safety risk associated with products, interest to achieve a competitive advantage, willingness to pay for technology use and interest of consumers to be involved in decision making as drivers for Blockchain adoption in the fresh produce supply chain in the UK. Meanwhile the fear of disruption on current operating systems and processes, fear of antagonizing competition, pay-back on investment not demonstrated, and lack of education on the technology; act as barriers to impede the adoption of Blockchain in the fresh produce supply chain.

This study into the opportunities for Blockchain in fresh produce supply, identifies the novelty and complexity of UK fresh produce supply chain as the main barriers hindering Blockchain adoption, but foresees a change in technology reception should customers (retailers) push for its consideration.

Further qualitative and quantitative studies should be carried out on the adoption of Blockchain based solutions by farmers and food manufactures to understand whether the technology will contribute to add trust to their operations. 


\section{REFERENCES}

Abeyrantne, and Monfared. (2016). Blockchain ready manufacturing supply chain using distributed ledger. International Journal of Research in Enginering and Technology, 1-10.

Almeida, S., Albuquerque, A., and Silva, A. . (2019). An Approach to Develop Software that Uses Blockchain. R. Silhavy (Ed.), Advances in Intelligent Systems and Computing. Cham: Springer, pp. 346-355. doi:10.1007/978-3-319-91186-1_36

Bessems, P., and Bril, W. (2017). Blockchain Organiseren. Germany: Paul Bessems en Walter Bril.

Buterin, V. (2013). A next generation smart contract and decentalized application platform. Etherum White Paper, 1-36. Retrieved from http://blockchainlab.com/pdf/Ethereum_white_papera_next_generation_smart_contract_and_decentralized_application_platform-vitalik-buterin.pdf

Canavari, M. (2010). Traceability as part of cometitive strategy in the fruit supply chain. British Food Journal, 171-185.

Canavari, M., Centonze, R., Hingley, M., and Spadoni, R. (2010). Traceability as part of competitive strategy in the fruit supply chain. British Food Journal,, 112( 2), 171-186. doi:10.1108/00070701011018851

CBI. (2015). CBI Trade Statistic: Fresh Fruit and Vegetables. The Hague: CBI. Retrieved from www.cbi.eu/market-information

Evenstad, L. (2018, July 03). Food Standards Agency Pilot blockchain in slaughterhouse. Food Standards Agency . London: ComputerWeekly. Retrieved from computerweekly.com/news/252444137/Food-Standards-Agency-pilots-blockchain-inslaughterhouse

Gausdal, A. H. (2018). Applying Blockchain Technology: Evidence from Norwegian Companies. Sustainability , 1-16.

Ge, L., Verdouw, C., Wolfert, S., and Bogaardt, MJ. (2017, February 7). Big Data in Smart Frming-A review. Agricultural Systems, pp. 69-80.

Hingley, M. (2005a). Power imbalanced relationships: Cases frm UK fresh food supply. International Journal of Retail and Distribution Management, Special Issue, 33(8), 551-569.

Hingley, M. (2005b). Power to all our friends? Living with imbalance in. Industrial Marketing Management, 34(8), 848-858.

Hingley, M., and Sodano, V. (2010). Channel management and differentiation strategies in the supply chain for fresh produce. Journal of Food Products Marketing, 16(1), 129-146.

Hingley, M., Lindgreen, A., and Casswell, B. (2006). Supplier-Retailer Relkationships in the UK Fresh Produce Supply Chain. Journal of International Food Products and Agribusiness Marketing, 18, (1/2), 49-89. 
Huumo, K. D. (2016). Where Is Current Research on Blockchain Technology?-A Systematic Review. PLOS ONE, 1-27.

Kairos Future. (2018). Blockchain use cases for food traceability and control. Stockholm: Kauros Future. Retrieved from Kairos Future: https://www.kairosfuture.com/.../blockchain-use-cases-for-foodtracking-and-control/

Koc, T. (2017). Measuring the degree of novelty of innovation based on Porter's value chain approach. European Journal of Operational Research, 559-567.

Maras, and Elliot. (2017, May 3). Fast Casual. Retrieved from FastCasual.com:

https://www.fastcasual.com/articles/how-blockchain-technology-brings-new-efficiencies-andtransparency-to-the-food-supply-chain/

Mee, C. a. (n.d.).

Meyer-Larsen. (2014). Accelerating the Innovation Uptake in Logistics. In Blecker, Innovation Methods in Logistics and Supply Chain Management (pp. 4-22). Hamburg: HICL.

Nakamoto, S. (2008). Bitcoin. Retrieved from Bitcoin.org: www.bitcoin.org

O'Keeffe, and Fearne. (2002). From commodity marketing to category management: insights from the Waitrose category leadership program in fresh produce. Supply Chain Management: An International Journal, 7(5), 296-301. doi: https://doi.org/10.1108/13598540210447737

Pierce, J. (2018). The FSA's journey with the Blockchain: unexpected insights. London: Blockchainlive. Retrieved from www.blockchainlive.com

Tripoli, M., and Schmidhuber, J. $(2018,08)$. Emerging Opportunities for the Application of Blockchain in the Agri-food Industry. FAO and ICTSD, Issue Paper, 1-40.

Tuschl, M. (2017). European Ecommerce Report. Brussels (Belgium): Ecommerce Foundation. Retrieved from www.ecommercefoundation.org/reports

Vujičić D., Jagodić D., \& Ranđić S. (2018). Blockchain Technology, Bitcoin and Ethereum, A Brief Overview. 17th International Symposium INFOTEH-JAHORINA, 21-23 March 2018. Čačak, Serbia: IEEE.

White, G.R.T. (2017, 05 26). Future applications of blockchain in business and. Strategic Change, 26(5), pp. 439-451. doi:10.1002/jsc.2144

Wilson, I. (1994, August). Strategic Planning Is't Dead-It Changed. Long Range Planning Vol.24, N0.4, pp. 12-24. doi:10.1016/0024-6301(94)90052-3

Wilson, N. (1996). The supply chains of perishable products in northern Europe. British Food Journal, 98(6), 9-15. doi: 10.1108/00070709610131320

Yiannas, F. (2018). A new era of food tranarency powered by Blockchain. Innovations/Bockchain for Global Development , 12, pp. 46-56. 